\title{
GAIA Level 1 Gestational Hypertension
}

National Cancer Institute

\section{Source}

National Cancer Institute. GAIA Level 1 Gestational Hypertension. NCI Thesaurus. Code C128009.

GAIA Level 1 Gestational Hypertension is defined by four criteria: first, the gestational age of the pregnancy must be greater than or equal to 20 weeks; second, a diagnosis of new onset maternal hypertension (systolic blood pressure greater than or equal to $140 \mathrm{mmHg}$ and/or diastolic blood pressure greater than or equal to $90 \mathrm{mmHg}$ ) that is sustained on two measurements over a minimum of one hour; third, the absence of any severe features (see preeclampsia with severe features category); fourth, the absence of proteinuria (as defined by 24 hour urine collection less than $300 \mathrm{mg}$, and spot protein:creatinine ratio less than 0.3 ). 